This is the author's Post-print version (final draft post-refereeing as accepted for publication by the journal). The definitive, peer-reviewed and edited version of this article is published as: Kleinhans R., van Ham M. \& Evans-Cowley J. (2015) Using Social Media and Mobile Technologies to Foster Engagement and Self-organisation in Participatory Urban Planning and Neighbourhood Governance. Planning Practice \& Research 30(3), 237-247. DOI: http://dx.doi.org/10.1080/02697459.2015.1051320

\title{
Using Social Media and Mobile Technologies to Foster Engagement and Self-organisation in Participatory Urban Planning and Neighbourhood Governance.
}

\author{
Dr. Reinout Kleinhans ${ }^{1}$, Prof. Dr. Maarten van Ham ${ }^{1,2}$, and Prof. Jennifer Evans-Cowley ${ }^{3}$. \\ ${ }^{1}$ Delft University of Technology, Faculty of Architecture and the Built Environment, \\ Department OTB - Research for the Built Environment \\ PO Box 5043, 2600 GA Delft, The Netherlands \\ Email: r.j.kleinhans@tudelft.nl (corresponding author)\& m.vanham@tudelft.nl \\ ${ }^{2}$ University of St Andrews, UK \\ ${ }^{3}$ The Ohio State University, College of Engineering, Knowlton School of Architecture. \\ Email: cowley.11@osu.edu
}

\section{Introduction}

This editorial explores recent research regarding the potential of ICT, social media and mobile technologies to foster citizen engagement and participation in urban planning. Public participation in urban and neighbourhood planning has been a hallmark of the planning process for over several decades, ranging from almost 50 years in the UK to very recently in some Eastern European countries. Over time, each generation of urban planners has tried to improve the participation and involvement of ordinary citizens (Evans-Cowley \& Hollander, 2010: 405). In this era of almost ubiquitous Internet accessibility, increasing attention and resources are devoted to new technologies in the search for meaningful and democratically legitimate citizen engagement.

In this editorial, we will argue that there is much wishful thinking, but little empirically validated knowledge in this emerging field of study of digitally supported engagement. We will outline some of the key developments and pay attention to larger societal and political trends, such as welfare state retrenchment, which reshape the ways in which citizens, public and private sectors interact and hence provide new contexts for citizen engagement. The overall aim of this special issue is twofold: 1) to offer a critical state-of-the- 
art overview of empirical research on the mobilising and engaging potential of social media and mobile technologies in the context of participatory urban planning; and 2) to explore whether social media and mobile technologies have measurable effects on citizens' engagement beyond traditional mobilisation and participation tools.

After sketching the wider context, we shortly introduce each of the contributions to this special issue of Planning Practice \& Research. The editorial is concluded by outlining some 'lessons learned' from the various contributions. While there is a clear engaging potential of social media, online platforms and mobile technologies, several conditions must be met. Wider engagement only materializes if virtual connections also manifest themselves in real space through concrete actions, and only if a range of both online and offline engagement tools is used. Another clear requirement is that planners do not seek to marginalise dissenting voices in order to promote the interests of powerful developers.

\section{Public Participation and the Turn to Technology}

Over time, urban and planning researchers have studied various ways to increase and improve collaboration, communication and interaction between 'experts' and the 'public' in the planning process (e.g. Friedmann, 1973; Healey, 1997; Brownill \& Parker, 2010: Jones et al., 2015, this issue). Essentially, public participation is considered to be "a cornerstone of democracy" (Roberts, 2004: 315), in which democratic legitimacy strongly depends on the nature and quality of public decision-making (Patten, 2001). Citizens' satisfaction with government responsiveness is associated with their perceived influence (i.e. participation outcomes) on decision-making (Brown \& Chin, 2013).

Conventional citizen participation methods that have been developed since the 1960s include a whole range of tools and tactics: referenda, public hearings, public surveys, conferences, town hall meetings, public advisory committees or focus groups (Rowe \& Frewer, 2000; Shipley \& Utz, 2012). A key characteristic of most methods is that they require citizens to be physically present at a particular time and place. This characteristic is associated with a range of practical problems of participation, such as limitations of time and costs in the process of policy-making, lack of motivation among citizens, weak citizen expertise or difficulties of including socioeconomically disadvantaged and less articulate groups in the process (Irvin \& Stansbury, 2004; Roberts, 2004; Shipley \& Utz, 2012; Ertiö, 2015 , this issue). This has resulted in a range of criticism aimed at traditional methods to involve citizens, boldly expressed in a seminal article on the US situation by Innes and Booher (2004):

"It is time to face facts we know, but prefer to ignore. Legally required methods of public participation in government decision making in the US-public hearings, review and comment procedures in particular-do not work. They do not achieve genuine participation in planning or other decisions; they do not satisfy members 
of the public that they are being heard; they seldom can be said to improve the decisions that agencies and public officials make; and they do not incorporate a broad spectrum of the public. Worse yet, these methods often antagonize the members of the public who do try to work with them" (ibid.: 419).

Scholars and policymakers have turned their attention increasingly towards contemporary technologies in order to overcome (some of) the aforementioned problems. Below, we review a few trends and technologies, without striving to be exhaustive in our review.

The end of the 1990s witnessed the rise of Geographic Information Systems (GIS). Within the field of urban planning, the empowering potential of GIS was quickly recognised for several reasons, such as the opportunity to open spatial information to all stakeholders (presumably leading to better policymaking) and the idea that spatial analysis and outputs (i.e. maps) can persuasively convey ideas (Sieber, 2006: 491). Several applications in the field resulted in the proliferation of public participation geographic information systems (PPGIS), which were supposed to increase informed citizen participation in decision-making.

More recently, innovative and imaginative geo-visualization interfaces such as Google Maps or Open Street Map - made possible by Web 2.0 technologies - have created lowkey opportunities for almost any citizen with an Internet connection to generate and publicize their own maps and geographic information (Adams, 2013: 464). Smartphones are now using GPS technologies that enable 'geo-tagging' of either physical objects in real life or online content, as well as providing location-aware information. In this context, Goodchild (2007) coined the term volunteered geographic information (VGI): digital spatial data created by individuals who use geo-visualization interfaces to disseminate their data (see also Sui et al., 2013).

The use of social media and mobile communication technologies has grown rapidly over the last ten years and has facilitated a constant increase in the number of virtual networks. The popularity of Facebook, Twitter, Google+, Instagram, Youtube, Blogspot and other social media has spurred a demand for new forms of participatory planning and selforganising governance by citizens. Unlike with many conventional methods, citizens are keen on using social media tools to engage with planners (Williamson \& Parolin, 2012; EvansCowley \& Hollander, 2010). Changing the relationship between citizens and government is often cited as a goal for digital government, also referred to as e-government, and new tools and social media have the potential to improve interactions with citizens through dialogue (Mossberger et al., 2013: 351).

In fact, the utility of social media has long gone beyond desktop computers with Internet connections. Popular social media are more easily accessible from smartphones than from traditional desktops as many people have $24 / 7$ access to smartphones. Compared to other forms of participation, this portability is a major advantage as it removes barriers of access according to the "online whenever wherever" principle and allowing participation "on the go" (Tertiö, 2015, this issue). Mobile participation, i.e. the mobile form of e-participation, is defined as "the use of mobile devices to broaden the participation of citizens and other stakeholders by enabling them to connect with each other, generate and share information, 
comment and vote" (Höffken \& Streich, 2013: 206). Mobile participation is expected to attract a much wider interest group than conventional participation tools, in particular youths and young adults who are difficult to engage in public affairs or participation schemes (Clark et al. 2013). The flip side of the coin is that other categories, e.g. older people, may not feel comfortable with using new technologies.

A more exotic, but potentially promising technology for citizen engagement involves digital visioning techniques using gaming strategies. With PPGS as a kind of predecessor, computer aided design, virtual environments, and digital games are all methods of obtaining user 'immersion' in a sensory and imaginative way (Gordon et al., 2011). For example, Gordon and Koo (2008) had their participants working with undergraduate students to build their fantasy version of a future park space in Boston, MA, with the 3D gaming platform Second Life to explore how communities understood the challenges facing their city and possible responses (Jones et al., 2015, this issue; see also Evans-Cowley \& Hollander, 2010).

Technological developments open up a range of possibilities and all over the world there are bottom-up experiments with new technologies. However, many developments, especially in the context of 'smart cities' are very much technology-driven and not user driven. Little is known about how effective new technologies are in overcoming the main obstacles of traditional ways to involve citizens in urban planning and governance.

\section{Beyond technology: from public participation to self-organisation}

ICT, social media and mobile technologies alter the larger context of public participation because they open up new possibilities for policy makers, but perhaps more importantly, they empower and foster the self-organisation of citizens. Social media are a powerful tool for citizen mobilization. Dramatic examples are the organised demonstrations in Arab countries such as Egypt during the 'Arab Spring' and riots in the English cities London and Manchester in 2011. Benign manifestations of self-organisation are timely in a context of neoliberalism and welfare state retrenchment, which have shifted the economies of advanced western states and are reshaping the ways in which citizens, public, private and third sectors interact with each other (Jessop, 2002; Brenner, 2004).

Due to the economic crisis, many European countries are implementing austerity measures and cuts in public policy, alongside longstanding trends of welfare retrenchment. Against this backdrop, governments and other institutions are searching for alternative ways to organise societies and to provide services, with more emphasis on the role of citizens themselves. This trend is visible in health care, but also in the context of urban planning, most noticeably in urban regeneration projects. The idea is to recast state-citizen relations, to promote civil society and to empower citizens to help themselves (Wells, 2011), especially in deprived urban areas. This trend is reflected in conceptions such as the 'Big Society' and 'localism' (United Kingdom), the 'participation society' (The Netherlands) or 'do-it-yourself urbanism in the United States and other countries around the world (Iveson, 2013; Finn, 
2014; Sawhney et al., 2015, this issue). Active citizenship, promoting citizens' selforganisation and engagement in urban development are high on the political agenda. As a result, many cities are experiencing a surge in place-based and technology initiatives, both government-initiated and grassroots activism, and collective networked action to foster civic engagement in urban and neighbourhood contexts.

To overcome the problems of participation as described in the previous section, many governments have turned to social media and social networking tools, with three potential communication strategies: (1) representation; (2) citizen engagement; and (3) networking with the public. The networking approach emphasizes a dialogue whereas engagement invites co-production of content without necessarily engaging contributors in dialogue (Mossberger et al., 2013: 353). However, research has shown that local governments predominantly stick to representation, applying 'push strategies' to provide one-way information (Mergel, 2013a, 2013b). According to Buccoliero and Bellio (2010: 236), there is a substantial immaturity of web strategies which are modulated on structures and organizational responsibilities instead of on the needs of citizens' empowerment. There are few studies that measure the real interaction with stakeholders, and even fewer focusing on how content type influences user engagement (Bonsón et al., 2015: 52).

In sum, while theories of deliberative democracy state that two-way or multi-actor deliberation is rather important for democratic practice (Gutmann \& Thompson, 2004), real two-way communication and networking between residents, governments and policymakers through social media is still scarce. Governments have not yet been able to tap effectively into citizens' online social networking practices that are part of citizens' daily routines. The same applies to the use of social media as tools for crowdsourcing that replace traditional data collection or funding mechanisms, in particular in grassroots movements, bottom-up initiatives and new forms of urban regeneration led by citizens (Seltzer \& Mahmoudi, 2012; Stiver et al., 2015). The capacity to access the expertise of quieter voices is acknowledged as a key advantage in online crowdsourcing approaches in participatory planning (Brabham, 2009; Jones, 2015, this issue).

While technology offers promises, it is not a panacea. Critics have argued that cities are looking to much to technology to solve problems. Critics state that cities are the people within them, not just the technologies, buildings, and infrastructure (Greenfield, 2013; Morozow, 2013; Townsend, 2013). Townsend (2013) points out that within the next 100 years more cities will be built than in all of human history, providing a key role for supportive technology. Yet, Greenfield (2013) argues that cities should not be planned with technology as the foundation, because the result is not a city designed to serve the interests of the people who will live there. It is the people focus that makes public engagement so important - having an inclusive participatory society. 


\section{About This Special Issue}

Considering the aforementioned trends and context, it is now timely to critically explore the potential of social media and mobile technologies. There is much wishful thinking, but little validated knowledge on the utility, mobilising potential and effectiveness of social media and mobile applications in creating either meaningful public participation or facilitating selforganisation by citizens who are taking over the reins in providing services and local regeneration efforts. We need to have stronger empirical evidence of what really works, what does not, who is included, who is left behind, and how the future of planning will grapple with the persistent problems of unequal power relations both online and offline (Evans-Cowley \& Hollander, 2010: 406). And what are preconditions and restrictions for effectively using the available technologies?

In sum, the aim of this special issue of Planning Practice and Research is twofold:

1. To offer a critical state-of-the-art overview of theory and empirical research about the mobilising and engaging potential of social media and mobile technologies in the context of participatory urban planning.

2. To explore whether social media and mobile technologies have measurable effects on citizens' engagement, self-organisation, and neighbourhood governance beyond traditional mobilisation and public participation tools.

The articles in this special issue are the result of the international research conference 'Using ICT, Social Media and Mobile Technologies to Foster Self-Organisation in Urban and Neighbourhood Governance', that was held at Delft University of Technology in the Netherlands, 16-17 May 2013 (www.otb.tudelft.nl/socialmedia). The aim of this conference was to identify and discuss scientific research into local experiences with the mobilising potential of social media and mobile technologies. Most participants were from academia, but delegates from local governments, NGOs, housing authorities and resident organisations also attended.

In the first article, Bonnie Johnson and Germaine Halegoua come straight to the point by asking whether social media can save a neighbourhood organisation. Focussing on the Indian Hills neighbourhood in Lawrence, Kansas (USA), they analyse how a failing neighbourhood organization tries to revive itself using social media. Survey results revealed that the respondents choosing social media as a preferred method of communication are those residents most interested in having an active neighbourhood association. However, several other factors explain the limited take-up, such as lack of skills, personal preferences against using social media and a mismatch between the nature of neighbourly ties versus more intimate ties associated with friends on social media. Johnson and Halegoua conclude that communication via social media might be a good en efficient way to 'jumpstart' a failing neighbourhood association, but that a wider, more 'inclusive' resident engagement can only be achieved by deploying a diverse range of engagement tools. 
Nader Afzalan and Jennifer Evans-Cowley also seek to understand the role of information technology in supporting information sharing and social connectivity at neighbourhood level. Examining Facebook neighbourhood groups, they show how members interact and connect. A deeper exploration of three neighbourhood groups reveals the ways in which members share information. Using content analysis, descriptive statistics and network analysis, the authors find that Facebook is a tool for supporting local information sharing and social connectivity, although the extent of these self-organizing systems varies across groups, some with tightly knit neighbourhoods and others with loose connections.

The article of Liisa Horelli, Joanna Saad-Sulonen, Sirkku Wallin and Andrea Botero offers a comparative qualitative analysis of two case studies in Helsinki. In order to deal with the complexities of "digitally mediated glocal everyday life" (Horelli et al., 2015, this issue), the authors coin the term 'expanded urban planning', which is based on communicative and post-structural planning theories (e.g. Healey, 1997), but focuses more on local community development, partly through including urban informatics in different phases of the planning cycle. The authors show how expanded urban planning enables the mobilization of different groups around issues related to urban space and materializes in temporary uses of places, event making and community development through bottom-up cultures. However, they conclude that insufficient links to decision-making constrains new solutions and creative actions.

Recently, the use of mobile technologies to engage with citizens has gained interest among researchers, policy-makers, and activists. In her article, Titiana-Petra Ertiö introduces a typology that identifies types of mobile applications (apps) supporting citizen participation in urban planning. Participatory apps in use around the world are plotted into the typology and their contribution is analysed with reference to the dimensions of the typology. Apps evolve from sharing information on the surrounding environment towards a dialogue aimed to accommodate citizen knowledge into the planning process. The article concludes that the impact of specific planning apps has yet been modest, but is expected to increase. Ertiö also discusses ways in which planning apps can leverage citizens' knowledge in the future.

In the same vein, Phil Jones, Antonia Layard, Chris Speed and Colin Lorne report on the development, testing and effectiveness of the tailor-made smartphone app MapLocal. This app seeks to empower residents to gather spatial data about their neighbourhood, fitting well with the literature on Volunteered Geographic Information (Goodchild, 2007; Adams, 2013; Sui et al., 2013). Responding to the new Neighbourhood Planning powers offered within the Localism Act of 2011, the authors conducted a pilot scheme with 50 participants across two neighbourhoods in Birmingham, UK. The MapLocal app allows crowdsourcing of knowledge from individuals to report on different characteristics of their neighbourhood and to undertake visioning exercises developing possible schemes to improve it. However, the authors argue that while citizens may generate very useful intelligence about potential 
development sites, they are not permitted to object to new developments under a planning system that is committed to a neoliberal agenda of growth (Jones et al., 2015, this issue).

In the final article of this issue, Nitin Sawhney, Christo de Klerk and Shriya Malhotra delve into practices of self-organisation and collective networked action. They start out from the phenomenon called DIY (do-it-yourself) urbanism, which can be shortly defined as shortterm, bottom-up urban transformations and place-making strategies that target longer-term changes in order to create vibrant, people-centred urban spaces. Sawhney and colleagues examine DIY urbanism through place-based and technology initiatives that support collective action to foster civic engagement in neighbourhood contexts. Based on participatory research and co-design with residents and urban activist groups, Delai Sam and Partizaning, in Moscow, Russia, the authors devised and simultaneously studied a series of interventions using a network of physical mailboxes, online platforms, and community-based workshops to engage residents in revealing issues, solutions, and coordinating urban actions. They observe that common digital problem-reporting approaches rarely seek to build capacity for collective civic engagement. Virtual connections among participants need to manifest in real space through concrete actions and effectiveness, while taking into account concerns of identity and anonymity, particularly in the case of politically engaged activities. Moreover, such collectivism must be inclusive to encompass the diverse demographics, motivations, and needs of residents, allowing cross-generational engagement, across socio-economic boundaries and technology-based access.

\section{Conclusions}

The articles in this special issue show a clear potential of social media, online platforms and mobile technologies for particular forms of citizen engagement. They offer several lessons regarding the necessary conditions for stronger citizen engagement.

Despite the promise of virtual networking, a clear message is that wider engagement will only 'materialize' if virtual connections also manifest themselves in real space through concrete actions and connections, and only if a range of both online and offline engagement tools is used in order to include both technologically-savy citizens and the 'slow adaptors'. Continued engagement, offline and online, will only occur if the rewards accrue to residents in the 'real world', in the form of neighbourhood improvements, better services, or events.

Notwithstanding empowering potential of social media and mobile technologies, ultimate decisions are usually still made by local governments and other authorities, who are not by default only serving citizens' interests. Apps such as MapLocal enable wider engagement with early phases of planning processes, but may simultaneously face attempts by growth-oriented urban planners to marginalise dissenting voices in order to promote the interests of powerful developers. The evidence of this tension between citizens' and community empowerment on the one hand and contracting out services and development 
to private, profit-maximizing developers on the other hand not only appears in England (see Painter et al., 2011; Raco, 2013, Jones et al., 2015, this issue), but also in many other European countries. In other words, social media and mobile apps can partially mitigate these post-political challenges to planning that is favouring powerful developers, but tipping the balance towards citizens being able to block unwanted projects in neighbourhoods is beyond the utility of ICT and mobile technologies.

Finally, we conclude that using social media and mobile technologies as tools to increase two-way interaction between citizens and (local) governments will not reduce the workload of professionals. While the discourse of active citizenship, financial austerity and government retrenchment favours citizens' taking matters into their own hands, seeking citizen involvement through social media and mobile technologies will probably increase the workload, because agencies need to be prepared to manage new flows of information and ideas from citizens (see also Seltzer \& Mahmoudi, 2012). The evidence presented in this special issue of Planning Practice and Research shows that this challenge is not yet properly addressed by governments. Technical advances must be embedded in proper governance structures in order to really stimulate citizens' engagement. Hence, 'smart cities' can only prosper with smart forms of governance.

\section{References}

Adams, D. (2013) Volunteered Geographic Information: Potential Implications for Participatory Planning, Planning Practice \& Research, 28(4), pp. 464-469.

Brabham, D. (2009) Crowdsourcing the public participation process for planning projects, Planning Theory, 8(3), pp. 242-262.

Bonsón, E., Royo, S., \& Ratkai, M. (2015) Citizens' engagement on local governments' Facebook sites. An empirical analysis: The impact of different media and content types in Western Europe, Government Information Quarterly, 32(1), pp. 52-62.

Brown, G. \& Chin, S. (2013) Assessing the effectiveness of public participation in neighbourhood planning, Planning Practice \& Research, 28(5), pp. 563-588.

Brownill, S. \& Parker, G. (2010) Why bother with good works? The relevance of public participation(s) in planning in a post-collaborative era, Planning Practice \& Research, 25(3), pp. 275-282.

Brenner, N. (2004). New State Spaces: Urban Governance and the Rescaling of Statehood. Oxford: Oxford University Press.

Buccoliero, L. \& Bellio, E. (2010) Citizens Web Empowerment in European Municipalities, Journal of E-Governance, 33(4), pp. 225-236.

Clark, B., Brudney, J., \& Jang, S. (2013) Coproduction of government services and the new information technology: investigating the distributional biases, Public Administration Review, 73(5), pp. 687-701. 
Evans-Cowley, J. \& Hollander, J. (2010) The new generation of public participation: Internetbased participation tools, Planning Practice and Research, 25(3), pp. 397-408.

Friedmann. J. (1973) Retracking America: a theory of transactive planning. New York: Anchor Press.

Goodchild, M. (2007) Citizens as sensors: the world of volunteered geography, GeoJournal, 69, pp. 211-221.

Gordon, E. \& Koo, G. (2008) Placeworlds: using virtual worlds to foster civic engagement, Space and Culture, 11(3), pp. 204-221.

Greenfield, A. (2013) Against the smart city (The city is here for you to use). Kindle Edition.

Gutmann, A. \& Thompson, D. (2004) Why deliberative democracy? Princeton, NJ: Princeton University Press.

Healey, P. (1997) Collaborative planning: shaping places in a fragmented society. Macmillan, London.

Höffken, S. \& Streich, B. (2013). Mobile participation: Citizen engagement in urban planning via smartphones, in: C. Silva (Ed.) Citizen E-Participation in Urban Governance: Crowdsourcing and Collaborative creativity, pp. 199-225. (Hershey: Information Science Reference).

Innes, J. \& Booher, D. (2004) Reframing public participation: strategies for the 21st century, Planning Theory \& Practice, 5(4), pp. 419-436.

Irvin, R. \& Stansbury, J. (2004) Citizen participation in decision making: is it worth the effort?, Public Administration Review, 64(1), pp. 55-65.

Jessop, B. (2002). The future of the capitalist state. Cambridge: Polity Press.

Mergel, I. (2013a) Social media adoption and resulting tactics in the U.S. federal government, Government Information Quarterly, 30(2), pp. 123-130.

Mergel, I. (2013b) A framework for interpreting social media interaction in the public sector, Government Information Quarterly, 30(4), pp. 327-334.

Morozov, E. (2013). To save everything, click here: Technology, solutionism, and the urge to fix problems that don't exist. New York: Allen Lane.

Mossberger, K., Wu, Y., \& Crawford, J. (2013) Connecting citizens and local governments? Social media and interactivity in major US cities, Government Information Quarterly, 30(4), pp. 351-358.

Painter, J., Orton, A., MacLeod, D., Dominelli, L. \& Pande, R. (2011) Connecting localism and community empowerment: research review and critical synthesis for the AHRC Connected Community Programme. Durham: Durham University. Available at: http://dro.dur.ac.uk/9244/1/9244.pdf (accessed 4 March 2015).

Patten, S. (2001) Democratizing the Institutions of Policy-Making: Democratic Consultation and Participatory Administration, Journal of Canadian Studies, 35, pp. 221-39.

Raco, M. (2013) The new contractualism, the privatization of the welfare state, and the barriers to open source planning, Planning Practice \& Research, 28(1), pp. 45-64.

Roberts, N. (2004) Public deliberation in an age of direct citizen participation, American Review of Public Administration, 34(4), pp. 315-353. 
Rowe, G. \& Frewer, L. (2000) Public participation methods: a framework for evaluation, Science, Technology, \& Human Values, 25(1), pp. 3-29.

Seltzer, E. \& Mahmoudi, D. (2012) Citizen participation, open innovation, and crowdsourcing: Challenges and opportunities for planning, Journal of Planning Literature, 28(1), pp. 3-18.

Shipley, R. \& Utz, S. (2012) Making it count: A review of the value and techniques for public consultation. Journal of Planning Literature, 27(1), pp. 22-42.

Sieber, R. (2006) Public participation geographic information systems: a literature review and framework, Annals of the Association of American Geographers, 96(3), pp. 491-507.

Stiver, A., Barroca, L., Minocha, S., Richards, M. \& Roberts, D. (2015) Civic crowdfunding research: Challenges, opportunities, and future agenda, New Media \& Society, 17(2), 249-271.

Sui, D., Elwood, S. \& Goodchild, M. (Eds.) (2013) Crowdsourcing Geographic Knowledge. Volunteered Geographic Information in Theory and Practice. Dordrecht: Springer.

Townsend, A. (2013) Smart cities: Big data, civic hackers, and the quest for a new utopia. London: WW Norton \& Company.

Wells, P. (2011) Prospects for a Big Society? Special Issue of People Place and Policy Online Guest Editorial, People, Place and Policy Online, 5(2), pp. 50-54.

Williamson, W. \& Parolin, B. (2012) Review of web based communications for town planning in local government, Journal of Urban Technology, 19(1), pp. 43-63. 